\title{
The Omnipresence of Television and the Ascendancy of Surveillance/Sousveillance in Ray Bradbury's Fahrenheit 451
}

\author{
Hassan Abootalebi \\ English Literature, Lorestan University, IRAN \\ e-mails: abootalebi2010@gmail.com
}

\begin{abstract}
This paper is an attempt to analyze Ray Bradbury's Fahrenheit 451(1953) under the light of Jean Baudrillard's notions on the media and the influences it exerts on people's daily lives, and with an eye to Michel Foucault's surveillance as well. The titlementioned work, it is suggested, portrays a representative sample of a culture where different fields including books, education, and history fall under the influence of the media. Bradbury presents a society in which its inhabitants are bombarded with excessive data transmitted through television most of which is detrimental and not reliable. It is concluded that the presented culture in the novel is a microcosm of contemporary societies where authorities keep their subjects under control, engendering an atmosphere of anxiety, trepidation and apprehension for subversive forces and therefore preclude any disturbance on the part of them.
\end{abstract}

Keywords: Fahrenheit 451; television, surveillance; Baudrillard, Foucault.

There is nothing more mysterious than a TV set left on in an empty room. It is even stranger than a man talking to himself or a woman standing dreaming at her stove. It is as if another planet is communicating with you.

(Baudrillard, America)

\section{INTRODUCTION}

Born in July 27, 1929 in Reims, France, Jean Baudrillard was a socialist, philosopher, theorist and critic. He moved to Paris to attend Sorbonne University. At the university, he studied German language and literature. This led him to translate works of such authors as peter Weiss, Bertolt Brecht, Karl Marx, and Friedrich Engles. His interest later on changed to sociology, provoking him to write his doctoral thesis Le System des Objects (The System of Objects) in 1966. Baudrillard has in recent years achieved a worldwide fame. His writing includes a wide range of subjects: media, war, Marxism, communications and history. His critique of Foucault led him into exclusion from sectors of academic influence. Influenced by Sartre, Baudrillard was politically radical. His works sometimes defy categorization, but they are overall associated with Postmodernism.

Regarding the significance of Baudrillard's writings and his way of thinking over the past few years and the influence he has exerted in different realms, says Hegarty (2004), "Baudrillard writes, and sometimes the world catches up" (p. 1). He is not only one of the prominent writers on postmodernism, but "somehow seems to embody postmodernism itself" (Lane, 2000, p. 1). What distinguishes Baudrillard from such theorists as Foucault, Lyotard, and Derrida, according to Hegarty (2004), is "the style of his writing." Compared to the above-mentioned figures, Baudrillard "except in his early writings, is the most intransigent of the lot, the one always beyond the pale, as nothing is to be accepted, no critique or method recommended, no academic convention followed" (p. 1). Acknowledged as one of the foremost intellectual figures, Baudrillard's theories are of paramount importance in the postmodern age. He is the one who has attracted much critical attention over the past few years. His theories are rather difficult to deal with. This can be thought of as their strength meaning his work became "theoretical objects" rather than being "pieces for someone else's puzzle" (Hegarty, 2004, p. 2). He is "the most notorious and immoderate of the thinkers associated with postmodernism" (Payneh, et $\mathrm{al}, 2010$, p. 57). His views on culture and mass media are to some degree far-fetching and extravagant, and have had an immense influence in different domains. 
Baudrillard's early works were known just in French, but after 1968 they were translated into English and thereafter he became known as one of the major theorists. His most widely read books include: Simulacra and Simulation (1995), and In the Shadow of the Silent Majorities (1978). The latter book is, according to Clarke (2009), "an extended meditation on the last chapter of Consumer Society" (p. 72). The book is best known for its "three hypotheses concerning the relationship between the social and what Baudrillard calls the masses" (Clarke, 2009, p. 72). The first hypothesis claims that "the social has basically never existed." The second is that "the social has really existed; it exists even more and more." The third one is that the "social has well and truly existed, but does not exist anymore" (p. 72). Then the world "was bombarded by Baudrillardian phrases such as simulation, simulacra, the hyperreal and the impossibility of meaning" (Lane, 2000, p. 20). The publication of Baudrillard's first book, The System of Objects (1968) was coincident with popular uprisings in France in which he argues that objects have been turned into commodities, no longer possessing their inherent value they once had. In the Consumer Society: Myth and Structures (1970), he expresses a contrary view from that of Marx, his focus is on consumerism, believing that the main drive in a capitalist society is not production, but consumption.

\section{BAUDRILLARD'S PERSPECTIVE TOWARDS THE MEDIA}

The media plays a cardinal role in today's world. No one can gainsay the influence it exerts on individuals dwelling in a particular society. It might be helpful, to begin with, to provide a concise account of the perspective Baudrillard takes towards the media. Information transmitted through the media, Baudrillard (1995) contends, "devours its content. It devours communication and the social" (p. 55). The rationale behind this claim is that:

Rather than creating communication, it exhausts itself in the act of staging communication. Rather than producing meaning, it exhausts itself in the staging of meaning. A gigantic process of simulation that is familiar...behind this exacerbated mise-en-scene of communication, the mass media, the pressure of information pursues an irresistible destruction of the social. (pp. 98100)

According to Baudrillard (1995), the sort of data coming from the media dissolves both meaning and the social in a vague way relating not to the 'surplus of innovation' but rather to 'total entropy', and only the media is capable of making an event whether 'conformist or 'subversive' (p. 56). The media, he argues, produces not 'socialization' rather it implodes "the social in the masses. And this is only the macroscopic extension of the implosion of meaning at the microscopic level of the sign" (p. 56). The inexorable messages and signs conveyed via the media, more often than not, refer to no particular reality. They refer to themselves in a seemingly circular process. The medium is itself the message signifying:

Not only the end of the message, but also the end of the medium. There are indeed no more media in the literal sense of the word-that is, of a mediating power between one reality and another, between one state of the real and another. Neither in content, nor in form. And this is what implosion means. (p. 57)

Information does not create communication, says he, but rather it is dissolved during the process of being conveyed, resulting in simulation. As a consequence of the unstoppable flow of data coming from the media, the differentiation between objects and their representation has become blurred, leading to the mingling of reality and simulation of reality. Finally, Baudrillard, regarding the destroyed meaning as a result of the circularity of data transmitted through the media, concludes that:

The fact of this implosion of contents, of the absorption of meaning, of the evanescence of the medium itself, of the reabsorption of every dialectic of communication in a total circularity of the model, of the implosion of the social in the masses, may seem catastrophic and desperate.(p. 57)

It is an axiomatic fact that the media, particularly over the past few years, has been a formidable power in shaping people's conducts and viewpoints, being highly successful in engendering effect in instilling sometimes fallacious notions into individuals who are not cognizant of the pernicious influence they might have on them. Baudrillard attempts to make people aware of these effects most of which detrimental and, indeed, difficult to fathom. He, however, views the media and the messages transmitted through it with a jaundiced eye, ignoring the positive effects they are capable of producing.

\section{FOUCAULDIAN SURVEILLANCE/ SOUSVEILLANCE}

One way, writes Mann (1998), "to challenge and problematize both surveillance and acquiescence to it is to resituate these technologies of control on individuals, offering panoptic technologies to help 
them observe those in authority. We call this inverse panopticon 'sousveillance' from the French words for 'sou' (below) and 'veiler' to watch" (p. 331). According to Mann (1998), sousveillance is a form of "reflectionism for a philosophy and procedures of using technology to mirror and confront bureaucratic organizations" (p. 333). By enabling the surveillee to surveil the surveiller, reflectionisms transforms the surveillance techniques into sousveillance and increases the equality between the watcher and the person being watched. Sousveillance distrupts the power relationship of surveillance.

Wearable computing devices afford possibilities for people to watch the watcher. Because of the mobility of the modern individual, individuals take their own sousveillance with them by mobile phones, computers, laptops and personal digital assistants. Sousveuillance in opposition to modern technologies of surveillance seeks various techniques of self-empowerment, liberation and obedience to authoritative watchers. As Mann (1998) puts it, "Universal surveillance/sousveillance may, in the end, only serve the ends of the existing dominant power structure of monitoring and ubiquitous data collection" (p. 347).

An effective way of taking people of a given community under control is surveillance by which authorities manage to impose strictures upon their subjects and to pre-empt possible disturbances. The main purpose of surveillance is to create malleable and docile individuals, to secure the position of those behind it. Surveillance, literally defined, is a careful watching of a person or place for fear of causing trouble on the part of recalcitrant forces. With the advent of new technology, formerly used strategies were supplanted by new ones so that the way surveillance was carried out became more and more less noticeable and tangible. Surveillance "would make it possible to prevent crimes" which are deviations from the norms, or if committed, to arrest their authors. "Therefore, in the absence of surveillance we would face an increase in the rate of crimes, deviations from the norms and transgressions of the rules" (Foucault, 1977, p. 96). Power "is now exercised in non-traditional locations like data ware houses, soft-ware, airline and phone companies" (Ball, et al, 2012, p. 38). Collecting information about people of a given community without any restriction illustrates the emergence of virtual or simulation of physical reality, a hyperreality. To put it succinctly, "In all these developments, simulation provided tools for overcoming limits of control embedded in panoptic model, limits tied to its form of enclosure and its conception of truth and reality" (p. 34).
The main target of Foucauldian surveillance has always been body where surveillance was directed to. In the age of information technology, however, data obtained from body rule over material body. Digitization processes in fact augmented the number of ways in which body can be observed, analyzed, categorized, and ultimately, managed. Moreover, "computer-power enhances the visibility of those whose details circulate within and between databases on a scale unimaginable to those whose gaze relies merely on window-light, blinds and uninterrupted vision" (Lyon, 2003, p. 92). "Although surveillance rests on individuals," says Foucault (1977), its functioning is that of a "network of relations from top to bottom, but also to a certain extent from bottom to top" (p. 176). It means that the observers are observed, too. The surveillance is not always hierarchical so that the elements of the higher ranks observe the behavior of the elements of the lower ranks and vice versa. Sometimes it is horizontal so that an element observes the behavior of another element of the same rank. It is the art of seeing without being seen which is the major characteristic of Bentham's Panopticon. The lack of comprehensive and constant surveillance in any disciplinary institute leads to failure in imposing power upon the inmates, because "all power would be exercised solely through exact observation; each gaze would form a part of the overall functioning of power" (Foucault, 1977, p. 171).

The surveillance system obtains personal and group data in order to "classify people and populations according to varying criteria, to determine who should be targeted for special treatment, suspicion, eligibility, inclusion, access, and so on" (Lyon, 2003, p. 20). This mode of contemporary surveillance eliminates individuality and uniqueness. Surveillance categorizes, sorts, influences and manages population and leads to social discrimination, differentiation and division.

\section{RAY BRADBURY'S FAHRENHEIT 451}

Bradbury is able to build on his ability to influence culture and to express his political ideology. In Fahrenheit 451 he creates a dark, futuristic world that does not want a well-educated, well-informed population, capable of critical thinking. According to the system, a good citizen is one who does not dare to form his own opinions. Complacent citizens willingly serve the system by letting the authorities make all the decisions for them. The system suffers from mass conformity and homogenization. Books are outlawed and the mindless society immerses itself in different kinds of distraction such as television, seashell radio, 
loud music, addiction, medication and fast automobiles as ways to being happy and to escaping from responsibilities and realities of life. Machines and the mass media are used as powerful tools for social control and eliminating differences and originalities.

Bradbury's work presents a dystopian community in which burning books is done by firemen and where written word is proscribed. Set in a near future, the book accentuates the role of the media in general, and television in particular, plays in different fields, and highlights how significant domains including books, education, and history are affected by the plethora of data conveyed to individuals through the media and authorities. The novel thus calls the readers' attention to the negative and pernicious effects of the media.

Television, in the above-mentioned book, does affect reading books. It is highly effective in putting books to the back of minds. Individuals no longer feel disposed to read books. The sort of information they need is provided via television, in a way which is faster and easier to gain access to than buying and reading books of any kind. This is patently obvious in the conversation between Mildred (Montag's wife), and Montag in which she believes people need not read books: "why should I read? What for? (p. 55). Or as it is asserted by Beatty (Montag's boss):

books cut shorter. Condensation, Digests, Tabloids. Everything boils down to the gag, the snap ending...classics cut to fit fifteen-minute radio shows, then cut again to fill a two-minute book column, winding up at least as a ten-or twelve-line dictionary resume. The dictionaries were for reference. But many were those whose sole knowledge of Hamlet (you know the title certainly, Montag; it is probably only a faint rumour of a title to you, Mrs. Montag) whose sole knowledge, as I say, of Hamlet was a onepage digest in a book that claimed: now at least you can read all the classics; keep up with your neighbours.” (Bradbury, 1953, p. 44)

Even Faber, a retired English professor, reinforces this idea, when talking to Montag struggling to convince him about the current status of books, that books have in recent years been superseded by other tools, and fallen into desuetude:

it's not books you need, it's some of the things that once were in books. The same things could be in the 'parlour families' today. The same infinite detail and awareness could be projected through the radios and televisions, but are not...books were only one type of receptacle where we stored a lot of things we were afraid we might forget. (p. 63)
The depicted society in Fahrenheit 45lis extremely uninterested in literature and do not believe it is capable of educating them. When Phelps sees a book of poetry carried by Montag, she seems surprised: isn't that a book? I thought that all special training these days was done by film" (p. 75). When Montag reads the poem Dover Beach by Mathew Arnold out to the women being in his house they evince no interest in it. It might be helpful to bring the muchquoted extracts from it:

"Ah, love, let us be true

To one another! for the world, which seems

To lie before us like a land of dreams,

So various, so beautiful, so new,

Hath really neither joy, nor love, nor light,

Nor certitude, nor peace, nor help for pain;

And we are here, as on a darkling plain

Swept with confused alarms of struggle and flight,

Where ignorant armies clash by night."

Being one of the most 'anti-victorian figures of his age', Arnold attacks his contemporary society for their lack of interest in literature and their materialism, for what he believes is wanting; 'sweetness and light' a phrase indicating 'reasonableness of temper and intellectual insight'. The novel can, therefore, be called, as Bloom (2008) puts it, a "work of Arnoldian social criticism without too much controversy" (p. $38)$.

The one who is deeply steeped in television, in 'TV parlour', and who feels reluctant to call into question the society's saturation with the media is Mildred. The characters appearing in television are, in her eyes, more real than her husband. Being extremely entangled in what Baudrillard names hyperreality (simulacrum), Mildred tries to create a world bereft of the real one in which she is given a false sense of happiness. She indeed attempts to wipe out her bitter memories of the past, and to pretend she is pleased with her married life. The constructed simulacrum is given priority over her husband. The simulacra, according to Moore (2010), "soon possess more authenticity within the household than Montag does" (p. 26). The following conversation between the couple illustrates the point:

"Will you turn the parlour off?" He asked.

"That's my family."

"Will you turn it off for a sick man?"

"I'll turn it down."

She went out of the room and did nothing to the parlour and came back. "Is that better?"

"Thanks."

"That's my favourite program," she said. (Bradbury, 1953, p. 38) 
The only character in the course of the novel who is against the use of the media and its ensuing effects being called 'anti-social' by others is Clarisse, a 17year-old girl, who remonstrates against, and rails at, the cumulative effect of using the media for purposes of education and sports which, she thinks, will engender ant-socialism among the public and people are given no opportunity to raise the queries they have:

an hour of TV class, an hour of basketball or baseball or running...we never ask questions, or at least most don't; they just run the answers at you, bing, bing, bing, and us sitting there for four more hours of film-teacher. That's not social to me at all (p. 22)

Another domain coming under the influence of television is education. Students, with the advent of new technology, are not taught by teachers any longer but by screens, therefore obviating the need for the presence of a professor to help students with their learning problems. This process gradually leads the role schools once used to have to become more and more less noticeable and effective:

school is shortened, discipline relaxed, philosophies, histories, languages dropped. English and spelling gradually neglected, finally almost completely ignored. Life is immediate, the job counts, pleasure lies all about after work. Why learn anything save pressing buttons, pulling switches, fitting nuts and bolts?" (p. 44)

Although technology has expedited the learning process, the type of information conveyed to students seem not to enhance the wisdom and intellect of people because, as Moore puts it, "it is the producers, and not the masses, that control the information being broadcasted" (p.17). As Beatty says:

Give the people contests they win by remembering the words to more popular songs or the names of state capitals or how much corn Iowa grew last year. Cram them full of noncombustible data. Choke them so dammed full of facts they feel stuffed, but absolutely brilliant with information. Then they'll feel they're thinking, they'll get a sense of motion without moving. And they'll be happy, because facts of that sort don't change. Don't give them any slippery stuff like philosophy or sociology to tie things up with. (p. 48)

History is as well deeply affected by television. It causes history to be distorted in a manner which makes people not have a recollection of the past occurrences and of those killed in wars. This effect is clearly observed on Mrs. Bowles by saying that: "I've never known any dead man killed in a war. Killed jumping off buildings, yes...but from wars? No" (p. 73). As a consequence of this distortion, people do not know that burning books was not always done by firemen. "The history," according to Moore (2010), "has been lost" (p. 37), because the world 'on the screen' is an "environment as real as the world. It becomes and is the truth" (p. 64). It should be noted, the author intimates that the failure to learn from history leads to repeating it. Montag is reminded by Granger of the fact that the sorts of the books being utilized by them will not suffice to save them:

even when we had the books on hand, a long time ago, we didn't use what we got out of them. We went right on insulting the dead. We went right in spitting in the graves of all the poor ones who died before us (Bradbury, 1953, p. 122).

Indeed, what Bradbury tries to insinuate is that we have become so addicted to television, so "antiintellectual, so afraid of thought," to quote Kagle (2008), that we cannot forswear using the media in matters of education. The media has become so influential that even education comes under the influence of it in a way that the merits of attending schools gradually disappears and students are encouraged to learn via the media instead. "The word intellectual," says Beatty, "of course, became the swear word it deserved to be. You always dread the unfamiliar" (as cited in Bloom, 2008, p. 46).

The government has proscribed reading or owning all books and the accumulation of any knowledge in order to repress individualism. The result is ignorant and pleasure-seeking society that can easily be controlled and manipulated. The submissive and conformist members of society have internalized the punishment associated with possessing books. Anyone who professes his or her individuality is seen as a threat. According to the system, they are not supposed to have opinions of their own as individual opinion and personal uniqueness may lead to confusion and unhappiness. To put it succinctly, they are not expected to think at all, just comply with the system. Since the ruling system does not allow any personal freedom, individuals are supposed to behave as the authorities expect them to do. The dominant surveillance demands people to be docile and obedient to the law. This represents the end of privacy and liberty, the total subjection of the individual to an invasive authority.. Montag has been trained to act according to the will of the state. He has internalized the rules of society and feels guilty about violating those values. He never questions why books should be burnt or never dares to open and read one of them. Not only are individuals subjected to the laws of the 
state regarding possessing and reading books, but they also actively participate in the surveillance and enforcement of the laws. In this case, they represent the docile and idealized bodies mentioned in Foucault's theories of social control. They passively and unquestioningly accept what the system considers right behavior and conduct. This situation is noticeable in the dialogue between Clarisse McCellan and Montag:

"Do you ever read any of the books you burn?"

He laughed. "That's agains the law!"

"Oh. Of course."

"It's fine work...burn 'em to ashes, then burn the ashes. That's our official

slogan.” (Bradbury, 1953, p. 7)

Considerable amount of time in school is devoted to sports so as to exhaust and tame young bodies, "hence in order to extract from bodies the maximum time and force, the use of those overall methods known as time tables, collective training, exercises, total and detailed surveillance" (Foucault, 1977, p. 220). However, the exhaustion felt by students turns to violence outside schools. Clarisse acknowledges that:

I'm afraid of children my own age. They kill each other. Did it always use to be that way? My uncle says no. Six of my friends have been shot the last year alone. Ten of them died in car wrecks. I'm afraid of them and they don't like me because I'm afraid. My uncle says his grandfather remembered when children didn't kill each other. But that was a long time ago when they had things different. (Bradbury, 1953, p. 14)

All schools are carefully organized and planned and put in order without replacement and omission. The timetable combined with the clock is a significant device for establishing rhythm and coordinating human activities in time and space. Timetable monitors a minute-to-minute activity. Furthermore, isolationist school system pays close attention to students spending too much time alone, or asking and answering any questions which could lead to collective interaction and opposing desire against the system. Additionally, by participating in critical discussions pupils would develop their own identities and ideas which contradict the main function of institution producing docile bodies that conform to norms.

\section{CONCLUSION}

As discussed above, Bradbury portrays a culture in which its denizens are bombarded with a plethora of information transmitted via television most of which having pernicious effects on them while a large majority are not cognizant of, and familiar with, these influences which lead to such other fields of importance as literature, education and history among them, to be overshadowed by the juggernaut of the media. Mildred, for example, is so sucked into television and its messages that for her, the simulacrum has priority over her husband and her real life. He gives more credence to what she is provided by television than what her husband says to him. Individuals are not willing to dismiss the data conveyed to them by the media and to lend credence to other sources of information which might be more reliable and less innocuous. Bradbury's novel can be thought of as a microcosm of contemporary societies in which no single place is immune to the surfeit of technology and its dire effects, and where those like Clarisse who are reluctant to be steeped in technology are called anti-social and shunned by society. Though behaving like others at the outset, Montag as time passes by, comes to realize the aforementioned effects emanating from the media and is therefore considered a maverick who must be jettisoned. The society of Fahrenheit 451 is a dystopian one in which by the virtue of imposing surveillance, its authority manage to successfully prevent any unrest and gain knowledge of the manner the people are ruled and taken under control.

No single theory or model is adequate to determine the pivot of contemporary surveillance, but important clues obtained from Baudrillard's hyperreal world, Bentham's panopticon vision and new surveillancel sousveillance theories indicate its focus on information gathering and techniques for social control and social fragmentation. Surveillance systems appear in political, economic and cultural contexts. Issues raised by surveillance have become central features of contemporary advanced societies. There is no escape from dystopian future; therefore, specific policies and informed actions are required to prevent the occurrence of possible catastrophes.

\section{REFERENCES}

Ball, K., Haggertay, M., Kevin, D., \& Lyon, D. (Eds). (2012). Routledge handbook of surveillance studies. London and New York: Routledge.

Baudrillard, J. (1995). Simulacra and simulation. Trans. Sheila Faria Glaser.

Bloom, H. (2008). Bloom's modern critical interpretations: Ray Bradbury's fahrenheit 451. New York.

Bradbury, R. (1953). Faranheit 451. New York: Ballantine.

Clarke, B., Doel, D. M., Merrin, W. \& Smith, R. G. (Eds). (2009). Jean Baudrrillard: Fatal theories. London and New York: Routledge. 
Foucault, M. (1997). Discipline and punish: Birth of the prison. Trans. Alan Sheridan. New York: Vintage.

Hegarty, P. (2004). Jean Baudrillard: Live theory. London: Continuum.

Lane, R. J. (2000). Jean Baudrillard. London: Routledge.

Lyon, D. (1994). The electronic eye: The rise of surveillance society. Minneapolis: $\mathrm{U}$ of Minessota Press.

(2003). Surveillance as social sorting. London \& New York: Routledge.
Mann, S., Nolan, J. \& Wellman, B. (2015, May 15). Sousveillance: Inventing wearable computing devices for data collection in surveillance environments. Surveillance and Society. Retrieved from http//:www.Surveillance-and-society. org. Moore, C. D. (2010, June 25). Fahrenheit 451: Temperature rising. Retrieved from http:// www. Surveillance-Bradbury.org.

Payneh, M. \& Barbera, J. R. (Eds). (2010). A dictionary of cultural and critical theory. $2^{\text {nd }} \mathrm{ed}$. UK: Wiley-Blackwell. 